\title{
Femtosecond Lasers in Ophthalmology
}

\author{
Duna Raoof-Daneshvar, MD and Roni M Shtein, MD, MS
}

Kellogg Eye Center, University of Michigan, Michigan, US.

\begin{abstract}
The use of the femtosecond laser in ophthalmic surgery over the last decade has resulted in the development of innovative procedures. The ultra-short infrared laser pulses of the femtosecond laser can be applied precisely and predictably with minimal collateral tissue damage, making it an ideal tool for highly precise ophthalmic surgery. Flap creation in laser in situ keratomileusis (LASIK) is the most common use of this laser. It can also be used for other corneal refractive procedures, lamellar and full-thickness corneal transplantation, and cataract surgery. This article summarizes recent advanced applying femtosecond laser technology in ophthalmology.
\end{abstract}

\section{Keywords}

Femtosecond, laser, laser in situ keratomileusis (LASIK), cataract, femtosecond laser-assisted corneal surgery, femtosecond laser-assisted keratoplasty, intracorneal ring segment, astigmatism keratotomy, femtosecond laser-assisted cataract surgery

Disclosure: The authors have no conflicts of interest to declare.

Received: January 16, 2013 Accepted: February 20, 2013 Citation: US Ophthalmic Review, 2013;6(1):38-41 DOI: 10.17925/USOR.2013.06.01.38

Correspondence: Roni M Shtein, MD, MS, Assistant Professor of Ophthalmology and Visual Sciences, University of Michigan WK Kellogg Eye Center, 1000 Wall Street, Ann Arbor,

MI 48105. E: ronim@med.umich.edu

The versatility, predictability, and unique properties of the femtosecond laser have allowed its application in multiple avenues of anterior segment surgery. Femtosecond lasers generate ultra-short pulses utilizing small amounts of energy and minimizing damage to any of the surrounding tissues.

In this article, we summarize the surgical techniques that have been developed in ophthalmic surgery utilizing the femtosecond laser since its approval by the US Food and Drug Administration (FDA) in 2001. The femtosecond laser was initially introduced for creation of corneal flaps for laser in situ keratomileusis (LASIK). Since then, the use of femtosecond lasers has expanded to other corneal surgeries and, more recently, to cataract surgery.

\section{Femtosecond Laser Principles}

The femtosecond laser is an infrared laser (wavelength: 1,053 nm) with ultra-short pulse duration (10-15 s). Given its short pulse duration, the femtosecond laser has the ability to deliver laser energy with minimal collateral damage to the adjacent tissue. Thermal damage to neighboring tissue in the cornea has been measured to be in the order of $1 \mu \mathrm{m} .{ }^{1}$ The tissue interaction this laser utilizes is known as photo-disruption, a process in which small volumes of tissue are vaporized resulting in the formation of cavitation gas (carbon dioxide and water) bubbles. ${ }^{2}$

Furthermore, the femtosecond laser is unique in that it can be focused anywhere within or behind the cornea and is capable, to a certain extent, of passing through optically hazy media, such as an edematous cornea. The laser may be applied in multiple geometric patterns including vertical, spiral, or zig-zag cuts.

\section{Femtosecond Laser Systems}

There are multiple commercially available femtosecond laser models:

- Intralase FS'M (Abbott Medical Optics, Abbott Park, Illinois);

- $\quad$ Femtec ${ }^{\circledR}$ (20/10 Perfect Vision, Heidelberg, Germany);

- VisuMax Femtosecond System ${ }^{\circledR}$ (Carl Zeiss Meditec, Jena, Germany);

- $\quad$ Femto LDVTM (Ziemer Group, Port, Switzerland); and

- Wavelight FS200® (Alcon, Fort Worth, Texas).

Systems designed specifically for cataract surgery include:

- LenSx (Alcon, Fort Worth, Texas);

- $\quad$ Catalys (OptiMedica®, Sunnyvale, California);

- Lensar (LensAR Inc., Orlando, Florida); and

- VICTUS (Technolas and Bausch and Lomb).

The early femtosecond laser systems operated with a low repetition rate (15 KHZ) and thus required higher energy to operate. The new devices have an increased repetition rate (as high as $150 \mathrm{KHz}$ ), which leads to utilization of less energy and shorter procedure duration. In addition, the devices vary in their programmed and customizable geometric cut patterns. Each laser system has distinctive features allowing it to be popularized for use in specific procedures. 


\section{Refractive Surgery}

\section{Laser In Situ Keratomileusis Flaps}

In ophthalmic surgery, the femtosecond laser was first popularized as an alternative to the mechanical microkeratome for the creation of LASIK flaps. The femtosecond laser is applied to the corneal stroma at a pre-calculated depth. Flap creation using the femtosecond laser has been compared with creation using the mechanical microkeratome. Reports have shown reduced higher-order aberrations ${ }^{3}$ and enhanced flap thickness predictability. ${ }^{4}$ In addition, the femtosecond laser offers more options in terms of flap thickness, side cut angle, hinge specifications, and firing patterns.

Complications associated with the use of femtosecond laser for LASIK flap creation are rare. The opaque bubble layer (OBL) forms along the cutting plane and may limit the ability of the surgeon or the excimer laser eye tracker to locate the pupil for centration. This can occur when cavitation bubbles escape into the deep corneal stroma, although most disappear spontaneously. Transient light-sensitivity syndrome (TLSS) is characterized by photophobia and pain that may appear days to weeks following LASIK with femtosecond laser flap creation. ${ }^{5}$ It typically resolves after aggressive treatment with topical steroids.

\section{Intracorneal Ring Segments}

Intracorneal ring segments (INTACS) are thin semicircular inserts made of polymethylmethacrylate that are implanted in the corneal stroma to shorten the arc length of the central corneal surface and result in corneal surface flattening. Intracorneal ring segments have been used to treat corneal ectatic disorders such as keratoconus and post-LASIK ectasia, as well as myopia. The femtosecond laser may be programmed to create tunnels for INTACS implantation. This technique has been shown to be comparable to manual tunnel dissection in terms of visual and refractive outcomes. ${ }^{6,7}$ The consistency of depth, uniformity of cut, and the minimal trauma induced when creating the channels using the femtosecond laser can make insertion of the INTACS easier and minimize the duration of the procedure. ${ }^{7}$

\section{Astigmatic Keratotomy}

Femtosecond laser-assisted astigmatic keratotomy has been primarily described for treatment of high astigmatism following penetrating keratoplasty. 8,9 As the femtosecond laser is capable of creating incisions with high precision and reproducibility, it can be used to control the desired length, shape, and depth of incisions for astigmatic keratotomy. Multiple studies have reported enhanced predictability and reduced complications rates, such as microperforation and decentration, in femtosecond laser-assisted astigmatic keratotomy compared with manual techniques. ${ }^{10,11}$ Axial topographic maps are used to identify the steep meridians and a standardized nomogram is used to generate a surgical plan with paired incisions for each patient.

\section{Femtosecond Laser-assisted Lenticule Extraction}

Femtosecond laser-assisted lenticule extraction (also known as FLEX) is used to correct myopia. The technique involves making two lamellar cuts in the cornea that intersect in the periphery, thus creating a lenticule that is removed. The lenticule is extracted through a traditional, femtosecond laser-created corneal flap. The removal of the lenticule

\section{Figure 1: Femtosecond Laser-assisted Keratoplasty with a Mushroom-shaped Pattern}

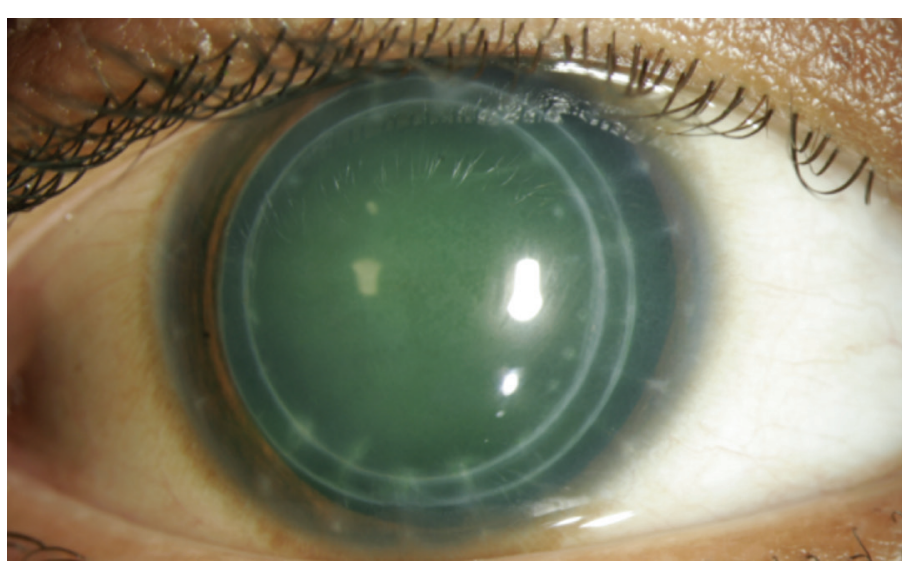

reduces the curvature of the cornea, subsequently reducing myopia. In a study by Blum et al., six-month results demonstrated that FLEx is both a safe and promising procedure for treatment of myopia. ${ }^{12}$

\section{Small Incision Lenticule Extraction}

This technique is similar to femtosecond laser-assisted lenticule extraction in that a corneal lenticule is extracted to correct myopia. However, the lenticule is removed though a small femtosecond laser-created side cut rather than a flap. As this procedure does not involve creation of a flap, it may result in lower incidence of dry eye and ectasia, and it also eliminates the potential of flap-related complications. Reports show promising results in correcting myopia at six months. 13,14

\section{Corneal Transplant}

\section{Femtosecond Laser Assisted Keratoplasty}

The femtosecond laser was approved for the creation of full and partial-thickness corneal incisions for keratoplasty in 2005. Prior to keratoplasty surgery, the desired incision pattern is first applied to the donor cornea then a corresponding pattern is applied to the recipient cornea using the femtosecond laser. The recipient incisions are left incomplete in order to facilitate transfer of the patient to the operating room. The uncut bridge is then dissected in the operating room and the keratoplasty is completed in similar manner to traditional keratoplasty surgery (see Figure 1).

Performing femtosecond laser-assisted keratoplasty (FLAK) has a few advantages over traditional penetrating keratoplasty. Different patterns of trephination cuts may be applied, such as top-hat, zig-zag, or mushroom shapes. These configurations result in greater surface area of graft-host contact, which translates to shorter healing time and faster suture removal. ${ }^{15-17}$ The mushroom configuration may be advantageous for keratoconus by providing a larger anterior refractive surface, while a top-hat pattern may be preferred in endothelial disease in order to replace more endothelial cells.

\section{Anterior Lamellar Keratoplasty}

Anterior lamellar keratoplasty consists of transplantation of the anterior layer of the cornea where only the anterior lamella is diseased, such 
as anterior corneal scars, degenerations, or dystrophies. Advantages of anterior lamellar keratoplasty include its less-invasive nature and reduced risk of rejection. Precise manual lamellar dissection is challenging, however. In a study by Yoo et al., the depth of the anterior corneal pathology was determined using anterior segment optical coherence tomography, and the femtosecond laser was used to prepare the donor tissue and recipient eye to successfully perform femtosecond laser-assisted anterior lamellar keratoplasty. ${ }^{18}$ The only reported complications included dry eye; otherwise no incidences of graft rejection, infection, or epithelial ingrowth were reported. Outcomes with femtosecond-laser anterior lamellar keratoplasty need to be evaluated further to determine benefits over standard anterior lamellar keratoplasty.

\section{Endothelial Keratoplasty}

Descemet's stripping endothelial keratoplasty has become the standard procedure for isolated posterior pathology such as Fuch's endothelial dystrophy and pseudophakic bullous keratopathy. The femtosecond laser has been utilized experimentally in preparation of donor tissue for endothelial keratoplasty as well as in vivo rabbit models. 19,20 Initial reports demonstrated preparation of a donor cornea using the femtosecond laser is safe. ${ }^{21}$ Cheng et al. subsequently reported the first femtosecond laser-assisted endothelial keratoplasty on a patient with pseudophakic bullous keratopathy. ${ }^{22}$ Four months postoperatively, the posterior corneal disk was clear, demonstrating a functional corneal endothelial layer. Potential limitations of femtosecond laser-assisted keratoplasty include loss of endothelial cells, difficulty with donor tissue handling, and a rough graft-host interface. Larger studies are necessary to refine this procedure.

\section{Cataract Surgery}

The femtosecond laser is currently being evaluated for its capacity to improve several steps of cataract surgery. In 2009, the FDA approved the femtosecond laser for performance of anterior capsulotomy for cataract extraction. For toric and multifocal intraocular lenses, centration of the capsulorhexis is especially important as decentration, tilt, or rotation of these lenses may cause visual aberrations such as halos or significant deviations from expected refractive outcomes. The ability of the femtosecond laser to produce predictable, consistent, and perfectly circular anterior capsulotomies might allow improved outcomes with premium intraocular lenses.

Femtosecond lasers can also be used to fragment the lens nucleus. Different cut patterns can be applied to the nucleus to help 'soften' it, which ultimately results in reduced amounts of ultrasound energy required during the phacoemulsification step of cataract surgery.

Clear corneal incisions are the most widely performed method of access into the anterior chamber during cataract surgery. The femtosecond laser may be used to create these corneal incisions. In a pilot study, corneal incisions created with the femtosecond laser were more stable than incisions created with the keratome. ${ }^{23}$ It is hypothesized that the true multiplanar configuration of the laser-created wound increases its resistance to deformation and leakage. In addition, for the treatment of astigmatism, partial thickness corneal incisions created with the femtosecond laser at the time of cataract surgery may enhance the accuracy and reproducibility of correction. ${ }^{24}$

In a prospective study of 200 eyes, $74.5 \%$ underwent laser capsulotomy, lens fragmentation, and corneal incisions using the femtosecond laser. Complications included small anterior capsule tags (10.5\%), anterior radial tears (4\%), posterior capsular rupture (3.5\%), and dropped nucleus (2 \%). ${ }^{25}$ The authors reported a steep-learning curve associated with initial use of the femtosecond laser for cataract surgery, followed by an eventual increase in ease and predictability once this new technique was mastered. Further large studies must be carried out to confirm the safety and efficacy of this new procedure.

\section{Femtosecond Laser Limitations}

Despite the successful and widespread use of the femtosecond laser in ophthalmic surgery, some limitations must be acknowledged. For many ophthalmologists and patients around the world, access to these costly lasers is a challenging limitation. Utilizing the laser in procedures that also require an operating room, such as keratoplasty or cataract surgery, can pose a further logistical problem if the laser system and operating room are not in close proximity. With increased surgical efficiency and improved patient outcomes, it is anticipated that this technology may become more accessible over time.

\section{Conclusion}

The femtosecond laser is capable of creating precise incisions and has a range of diverse applications in anterior segment surgery. It is initially and most commonly utilized for the creation of LASIK flaps, and the femtosecond laser's accuracy, predictability, and safety have allowed its application in other surgeries including keratoplasty and cataract surgery. Assessments of Improved patient outcomes and increased surgeon efficiency will confirm the value and future promise of the femtosecond laser in ophthalmology. 
1. Lubatschowski H, Maatz G, Heisterkamp A, et al., Application of ultrashort laser pulses for intrastromal refractive surgery, Graefes Arch Clin Exp Ophthalmol, 2000;238(1):33.

2. Juhasz $\mathrm{T}$, Loesel FH, Kurtz RM, et al., Corneal refractive surgery with femtosecond lasers, IEEE I Sel TOP Quantum Electron, 1999:5(4):902

3. Tran DB, Sarayba MA, Bor Z, et al., Randomized prospective clinical study comparing induced aberrations with Intratase and hansatome flap creation in fellow eyes: Potential impact on wavefront-guided laser in situ keratomileusis, J Cataract Refract Surg, 2005;31(1):97.

4. Chen S, Feng Y, Stonjanovic A, et al., IntraLase femtosecond laser vs mechanical microkeratome in LASIK for myopia: a systematic review and meta-analysis, J Cataract Refract Surg, 2012; 28(1):15

5. Muñoz G, Albarrán-Diego C, Sakla HF, et al., Transient light-sensitivity syndrome after laser in situ keratomileusis with the femtosecond laser incidence and prevention, $J$ Cataract Refract Surg, 2006;2075-9.

6. Kubaloglu A, Sari ES, Cinar Y, et al., Comparison of mechanical and femtosecond laser tunnel creation for intrastromal corneal ring segment implantation in keratoconus: Prospective randomized clinical trial, J Cataract Refract Surg, 2010;36(9):1556-61.

7. Rabinowitz Y, Li X, Ignacio T, et al., INTACS inserts using the emtosecond laser compared to the mechanical spreader in the treatment of keratoconus, $J$ Refract Surg, 2006;22(8):764-71.

8. Buzzonetti L, Petrocelli G, Laborante et al., Arcuate keratotomy for high postoperative keratoplasty astigmatism performed with the intralase femtosecond laser, $J$ Refract Surg, 2009;25(8):709-14.

9. Kumar NL, Kaiserman I, Shehadeh-Mashor R, et al. IntraLase-enabled astigmatic keratotomy for postkeratoplasty astigmatism: On-axis vector analysis, ophthalmology, 2010;117(6):1228.

10. Bahar I, Levinger E, Kaiserman I, et al., IntraLaseenabled astigmatic keratotomy for postkeratoplasty astigmatism Am J Ophthalmol, 2008:146(6):897.

11. Hoffart L, Proust $H$, Matonti $F$, et al., Correction of postkeratoplasty astigmatism by femtosecond lase compared with mechanized astigmatic keratotomy, Am J Ophthalmol, 2009;147(5), 779 .

12. Blum M, Kunert K, Schröder M, Sekundo W, Femtosecond lenticule extraction for the correction of myopia: preliminary 6-month results, Graefes Arch Clin Exp Ophthalmol, 2010;248(7):1019-27.

13. Sekundo W Kunert $K$, Russmann $C$, et al., First efficacy and safety study of femtosecond lenticule extraction for the correction of myopia: six-month results, I Cataract Refract correction of myopia: six-mc
Surg, 2008;34(9):1513-20.

14. Shah R, Shah $S$, Sengupta S, Results of small incision lenticule extraction: all-in-one femtosecond laser refractive surgery, I Cataract Refract Surg, 2011;37(1):127-37.

15. Farid M, Kim M, Steinert RF, Results of penetrating keratoplasty performed with a femtosecond laser zigzag incision initial report, Ophthalmology, 2007:114(12):2208.

16. Holzer MP, Rabsilber TM, Auffarth GU. Penetrating Keratoplasty Using Femtosecond Laser, Am J Ophthalmol, $2007 \cdot 143(3): 524-6$
17. Chamberlain WD, Rush SW, Mathers WD, et al., Comparison of femtosecond laser-assisted keratoplasty versus conventional penetrating keratoplasty, Ophthalmology, 2011;118(3):486-91

18. Yoo SH, Kymionis GD, Koreishi A, et al.. Femtosecond laser-assisted sutureless anterior lamellar keratoplasty Ophthalmology, 2008:115(8):1303-7.

19. Mian SI, Soong HK, Patel SV et al, In vivo femtosecond laser-assisted posterior lamellar keratoplasty in rabbits, Cornea, 2006;25(10):1205-9.

20. Soong HK, Mian S, Abbasi O, Juhasz T, Femtosecond laser-assisted posterior lamellar keratoplasty: Initial studies of surgical technique in eye bank eyes, ophthalmology 2005;112(1):44-9.

21. Sarayba MA, Maguen E, Salz J, et al., Femtosecond laser keratome creation of partial thickness donor corneal buttons for lamellar keratoplasty, J Refract surg 2007:23:58-65.

22. Cheng, YY, Schouten JS, Tahzib NG, et al., Efficacy and safety of femtosecond laser-assisted corneal endotheli keratoplasty: a randomized multicenter clinical trial, Transplantation, 2009;88(11):1294-302.

23. Masket S, Sarayba M, Ignacio T, Fram N, Femtosecond laser-assisted cataract incisions: architectural stability and reproducibility, I Cataract Refract Surg, 2010;36(6):1048-9.

24. He L, Sheehy K, Culbertson W, Femtosecond laser-assisted cataract surgery, Curr Opin Ophthalmol, 2011;22(1):43.

25. Bali SJ, Hodge C, Lawless M, et al., Early Experience with the Femtosecond Laser for Cataract Surgery, Ophthalmology, 2012:119(5):891-9. 